\title{
Static Culture Combined with Aeration in Biosynthesis of Bacterial Cellulose
}

\author{
Nadezhda A. Shavyrkina ${ }^{1,2}$, Ekaterina A. Skiba 1,2 , Anastasia E. Kazantseva ${ }^{1}$, Evgenia K. Gladysheva ${ }^{1}$, \\ Vera V. Budaeva 1,*(D), Nikolay V. Bychin ${ }^{1}$, Yulia A. Gismatulina ${ }^{1}$, Ekaterina I. Kashcheyeva ${ }^{1}$, \\ Galina F. Mironova ${ }^{1}$, , Anna A. Korchagina ${ }^{1}$, Igor N. Pavlov ${ }^{1,2}$ and Gennady V. Sakovich ${ }^{1}$
}

1 Bioconversion Laboratory, Institute for Problems of Chemical and Energetic Technologies, Siberian Branch of the Russian Academy of Sciences (IPCET SB RAS), 659322 Biysk, Russia; 32nadina@mail.ru (N.A.S.); eas08988@mail.ru (E.A.S.); sitnikova97.97@mail.ru (A.E.K.); evg-gladysheva@yandex.ru (E.K.G.); nbych@yandex.ru (N.V.B.); julia.gismatulina@mail.ru (Y.A.G.); makarova@ipcet.ru (E.I.K.); yur_galina@mail.ru (G.F.M.); yakusheva89_21.ru@mail.ru (A.A.K.); pawlow-in@mail.ru (I.N.P.); admin@ipcet.ru (G.V.S.)

2 Biysk Technological Institute, Polzunov Altai State Technical University, 659305 Biysk, Russia

* Correspondence: budaeva@ipcet.ru

check for updates

Citation: Shavyrkina, N.A.; Skiba, E.A.; Kazantseva, A.E.; Gladysheva, E.K.; Budaeva, V.V.; Bychin, N.V.; Gismatulina, Y.A.; Kashcheyeva, E.I.; Mironova, G.F.; Korchagina, A.A.; et al. Static Culture Combined with Aeration in Biosynthesis of Bacterial Cellulose. Polymers 2021, 13, 4241. https://doi.org/10.3390/ polym 13234241

Academic Editor: Rosica Mincheva

Received: 15 November 2021

Accepted: 2 December 2021

Published: 3 December 2021

Publisher's Note: MDPI stays neutral with regard to jurisdictional claims in published maps and institutional affiliations.

Copyright: (c) 2021 by the authors. Licensee MDPI, Basel, Switzerland. This article is an open access article distributed under the terms and conditions of the Creative Commons Attribution (CC BY) license (https:// creativecommons.org/licenses/by/ $4.0 /)$.

\begin{abstract}
One of the ways to enhance the yield of bacterial cellulose (BC) is by using dynamic aeration and different-type bioreactors because the microbial producers are strict aerobes. But in this case, the $\mathrm{BC}$ quality tends to worsen. Here we have combined static culture with aeration in the biosynthesis of BC by symbiotic Medusomyces gisevii Sa-12 for the first time. A new aeration method by feeding the air onto the growth medium surface is proposed herein. The culture was performed in a Binder-400 climate chamber. The study found that the air feed at a rate of $6.3 \mathrm{~L} / \mathrm{min}$ allows a $25 \%$ increase in the BC yield. Moreover, this aeration mode resulted in BC samples of stable quality. The thermogravimetric and X-ray structural characteristics were retained: the crystallinity index in reflection and transmission geometries were $89 \%$ and $92 \%$, respectively, and the allomorph I $\alpha$ content was $94 \%$. Slight decreases in the degree of polymerization (by $12.0 \%$ compared to the control - no aeration) and elastic modulus (by 12.6\%) are not critical. Thus, the simple aeration by feeding the air onto the culture medium surface has turned out to be an excellent alternative to dynamic aeration. Usually, when the cultivation conditions, including the aeration ones, are changed, characteristics of the resultant BC are altered either, due to the sensitivity of individual microbial strains. In our case, the stable parameters of BC samples under variable aeration conditions are explained by the concomitant factors: the new efficient aeration method and the highly adaptive microbial producer—symbiotic Medusomyces gisevii Sa-12.
\end{abstract}

Keywords: static culture; aeration; bacterial cellulose; Medusomyces gisevii Sa-12

\section{Introduction}

Bacterial cellulose (BC) is a polymer that is synthesized by microorganisms. Glucose is the monomer of $\mathrm{BC}$, as for cellulose of plant origin. $\mathrm{BC}$ is distinct in the $3 \mathrm{D}$ architecture of the network structure of ultrafine fibers whose thickness varies from 20 to $100 \mathrm{~nm}$ [1-6]. BC contains constitutionally no lignin and hemicellulose impurities [7] and exhibits high values of physicochemical characteristics such as mechanical strength, water-holding capacity and crystallinity. Moreover, the fundamental property of BC is its biocompatibility [1-6]. BC is used in various fields ranging from traditional technical and food industries to biomedicine. The use of BC as a part of the newest composites using the emerging technologies [8] is continuously expanding the application range of this magnificent polymer $[2,6,7,9,10]$.

The BC-producing bacteria are strict aerobes; therefore, the amount of oxygen dissolved in the growth medium has an impact on the biosynthesis of BC. Under static culture conditions, oxygen is a limiting factor for the ongoing intracellular metabolic processes 
and $\mathrm{BC}$ biosynthesis, and influences physicochemical properties of $\mathrm{BC}[11,12]$. The oxygen deficiency of the culture medium causes the microbial cell growth and $\mathrm{BC}$ biosynthesis to cease.

To overcome the said problem, researchers are being proposed to use dynamic culture and adopt different-type bioreactors for the scaled manufacture of BC.

Dynamic culture takes place with a forced oxygen feed into the growth medium stratum, resulting in BC particles of different sizes $(10 \mu \mathrm{m}$ to $10 \mathrm{~mm}$ wide) and of different shapes (sphere-like, ellipsoid-like, star-like, fibrous suspensions, pellets or irregular masses). That is, the growth medium undergoes perturbations under the dynamic culture, impeding the formation of an a BC gel-film in its in its entirety [1]. Exclusive applications were proposed for sphere-like BC samples, for example, for improved physical absorption, transport, and cross-linking of different compounds [13,14]. In addition, BC obtained by dynamic culture can be used, if there are no BC size and shape requirements, for example, in the manufacture of paper, desserts, in the design of composites, including 3D printing. However, dynamic culture generally leads to limited application fields [1].

It was shown in the studies $[15,16]$ that an excessive oxygen feed reduces the yield of BC. Thus, despite the increased rate of oxygen delivery into the nutrient medium, the dynamic and static culture methods at the same duration provide equal yields of $\mathrm{BC}$. The researchers ascribe the low BC yield to the resulting non-cellulosic mutants and genetically instable bacteria under the dynamic conditions $[17,18]$. Moreover, an alteration of physicochemical properties of BC, specifically the microstructure of BC fibers, a decrease in the polymerization degree and crystallinity index, and an impairment of mechanical behavior were observed [19,20].

The use of different-type bioreactors made it possible to improve the BC yield [21,22]; however, as in the case of dynamic culture, the appearance of BC changed and its characteristics deteriorated $[23,24]$. So, it is generally accepted that the use of static culture is preferable to preserve the physicochemical properties of $\mathrm{BC}[1,25]$.

This is the first study to have combined the static biosynthesis of BC with forced aeration. A new aeration method by feeding the air onto the growth medium surface rather than deep into the medium is proposed herein. We hypothesized that this would allow the BC quality to be stable, which is warranted only by static culture, and the BC yield to be enhanced by supplemental aeration.

\section{Materials and Methods}

\subsection{Microbial Producer}

Medusomyces gisevii Sa-12 (Scientific Center "Kurchatov Institute"-Research Institute for Genetics and Selection of Industrial Microorganisms, Moscow, Russia) was chosen as the primary culture for the biosynthesis of BC. This symbiotic culture, commonly known as Kombucha or tea fungus, is comprised of 10 genera of acetobacteria, which, in fact, produce a cellulosic gel-film, and about 25 genera of yeasts that provide a comfortable co-existence of BC-producing microorganisms. The composition of the culture has repeatedly been described in the literature $[26,27]$.

\subsection{Biosynthesis of Bacterial Cellulose}

For the biosynthesis of $\mathrm{BC}$, we used a semisynthetic nutrient medium that was prepared as follows: ionized water was brought to boil, and dry bohea black tea (at $5 \mathrm{~g} / \mathrm{L}$, which is equivalent to a black tea extractive content of $1.6 \mathrm{~g} / \mathrm{L}$ ) was added, infused for $15 \mathrm{~min}$ and filtered off, and then $20 \mathrm{~g} / \mathrm{L}$ glucose was added (OOO Promsintez, CAS No. 5996-10-1, Chapayevsk City, Russia). Tea is a mandatory ingredient of nutrient media for the symbiotic culture [28]. The optimum concentrations of glucose and tea to warrant a high yield of BC and a low formation of byproducts were identified in our previous study [29].

A culture medium obtained after 14-day cultivation of symbiotic Medusomyces gisevii Sa-12 on the said nutrient medium was employed as the inoculum. The inoculum volume 
was $10 \%$ of the nutrient medium volume; the yeast cell count was $13.0 \times 10^{6}$ in $1 \mathrm{~mL}$, and the acetobacteria cell count was $2.1 \times 10^{6}$ in $1 \mathrm{~mL}$.

Biosynthesis of BC was performed under static conditions but with forced air feeding. The culture was run in a Binder-400 climate chamber (Berlin, Germany) which has a thermostat function and is fitted with a main air supply line to the bottom of the chamber. The circulation and uniform distribution of the air was due to a fan located on the top of the chamber, and due to perforated side walls. The constant temperature conditions were thus maintained within the chamber space. The air feed rates in the chamber were $3.3 \mathrm{~L} / \mathrm{min}$, $6.3 \mathrm{~L} / \mathrm{min}, 9.2 \mathrm{~L} / \mathrm{min}, 12.3 \mathrm{~L} / \mathrm{min}$ and $16.7 \mathrm{~L} / \mathrm{min}$. These were equivalent to the air change rates of $0.5,0.9,1.4,1.8$ and 2.5 of the chamber volumes per hour, respectively. The climate chamber equipped with high efficiency particulate air filters was installed in a clean room. As the control, biosynthesis was run without aeration. The culture temperature was $27^{\circ} \mathrm{C}$, $\mathrm{pH}$ was not controlled, and the culture time was 24 days.

The culture was performed in $250 \mathrm{~mL}$ plastic containers. For each of the aeration modes, the inoculum was injected into the nutrient medium volume $(16 \mathrm{~L})$, afterwards a $200 \mathrm{~mL}$ culture medium was injected into 80 containers each. Ten containers were placed onto 8 chamber shelves each-representing widely spaced grids little impeding the air stream. Onto the chamber's bottom were put 8 ionized water containers $(200 \mathrm{~mL}$ water volume) to create the desired air humidity and reduce evaporation losses. Samples were collected every business day; the entire container was sampled. An ionized water container was put into the place of the growth medium container each that was removed. The air humidity was measured by a TK- 5 contact thermometer (OOO Techno-AS, Kolomna city, Russia). The air humidity was $89-94 \%$ throughout the experiment ( 24 days).

After the biosynthesis was complete, BC gel-films were removed from the growth medium and washed with water until the microbial cells and coloring agents of the nutrient medium were removed in full, by the procedure described [29].

The experimental data for each of the aeration rates were obtained in triplicate; the results were expressed as the mean and experimental errors (standard deviation in sampling).

\subsection{BC Yield}

The BC yield was calculated by Equation (1), where the BC yield was estimated as the quantity of the resultant dry $\mathrm{BC}$ with respect to the initial concentration of the carbon source-glucose:

$$
\eta=\frac{m_{\mathrm{BNC}}}{C_{\mathrm{g}} \cdot V \cdot 0.9} \cdot 100
$$

where $\eta$ is the $\mathrm{BC}$ yield, $\% ; m_{\mathrm{BNC}}$ is the $\mathrm{BC}$ sample weight on an oven-dry basis $(\mathrm{g}), C_{\mathrm{g}}$ is the glucose concentration in the medium $(\mathrm{g} / \mathrm{L}), V$ is the medium volume $(\mathrm{L})$, and 0.9 is the conversion coefficient attributed to the water molecule detachment upon polymerization of glucose into cellulose. The yield was calculated by the procedure reported [30].

\subsection{Analytical Techniques}

\subsubsection{Active Acidity}

The active acidity during the biosynthesis of BC was measured by an I-160 MI ion meter (OOO Izmeritelnaya Tekhnika, Moscow, Russia).

\subsubsection{Concentration of Reducing Sugars}

The level of reducing sugars (calculated in glucose equivalent) in the growth medium was controlled using 3,5-dinitrosalicylic acid (Panreac, CAS No. 609-99-4, Barcelona, Spain), which changed its color from yellow to red when reacted with the reducing sugar (RS). The coloring intensity and, correspondingly, the RS concentration were determined on a UNICO UV-2804 spectrophotometer (United Products \& Instruments, Dayton, NJ, USA) at a wavelength of $530 \mathrm{~nm}$. 


\subsubsection{Scanning Electron Microscopy of BC}

The degree of polymerization of the $\mathrm{BC}$ samples was measured by a viscometer using cadoxene as solvent (ethylenediamine, AO LenReaktiv, CAS No. 107-15-3, Saint-Petersburg, Russia; cadmium oxide, AO LenReaktiv, CAS No. 1306-19-0, Saint-Petersburg, Russia), as described [31].

\subsubsection{BC Degree of Polymerization}

Scanning electron microscopy (SEM) images to examine the microfibrillar structure of BC were acquired on a JSM-840 scanning electron microscope (JEOL Ltd., Tokyo, Japan).

\subsubsection{Thermomechanical Analysis}

The strength behavior of BC was measured on a Shimadzu DTG-60 thermomechanical analyzer (Kyoto, Japan): the test specimen was stretched at a rate of $5.0 \mathrm{~g} / \mathrm{min}$ starting from $0.0 \mathrm{~g}$ to the maximum load of $400.0 \mathrm{~g}$ until failure, at a temperature of $23.0^{\circ} \mathrm{C}$.

The thickness of the BC samples was measured by a ICh-10 I-class dial indicator thickness gauge (Kirov Factory "Kirovskiy Instrumentalshchik", Kirov city, Russia). A Shimadzu TMA-60 instrument (Kyoto, Japan) was used to measure the strength of the BC samples. The test samples were stretched at a rate of $5 \mathrm{~g} / \mathrm{min}$ to the maximum load of $500 \mathrm{~g}$, at room temperature.

The Young's modulus of elasticity was estimated by Equation (2):

$$
E=\sigma_{-} \mathrm{sx} /\left(\left(\varepsilon_{-} \mathrm{sx} / 100\right)\right)
$$

where $E$ is the Young's modulus of elasticity, MPa; $\sigma \_s x$ is the conventional yield limit, $\mathrm{MPa} ; \varepsilon \_s x$ is the relative elongation at yield, \%.

\subsubsection{Thermogravimetric Analysis}

Thermogravimetric analysis was performed on a Shimadzu DTG-60 thermomechanical analyzer (Kyoto, Japan) under the following conditions: the test specimen was heated at a rate of $10^{\circ} \mathrm{C} / \mathrm{min}$ to the maximum temperature of $600^{\circ} \mathrm{C}$ in nitrogen environment at a gas flowrate of $40 \mathrm{~mL} / \mathrm{min}$.

\subsubsection{X-ray Diffraction of BC}

X-ray structural characterization was performed on a DRON-6 monochromatic diffractometer (NPO Burevestnik, Moscow, Russia) with $\mathrm{Fe}_{\alpha}$ radiation at scattering angles of 3 to $145^{\circ}$. The spectral characteristics were calculated with the PdWin software package. The index of crystallinity and $\mathrm{I} \alpha$ allomorph content were determined by the procedures reported $[32,33]$.

The analyses were carried out using equipment provided by the Biysk Regional Center for Shared Use of Scientific Equipment of the SB RAS (IPCET SB RAS, Biysk, Russia).

\section{Results and Discussion}

\subsection{Variation of Culture Parameters during BC Biosynthesis}

3.1.1. Active Acidity and RS Concentration

Figure 1 displays the variations in active acidity level and reducing sugar (RS) concentration when Medusomyces gisevii Sa-12 was cultured at different aeration modes.

A decrease in the active acidity of the culture medium during the cultivation is typical of the Medusomyces gisevii Sa-12 microbial producer, and is explained by acetic, succinic, malic and gluconic acids being formed as metabolic products of the acetobacteria and yeasts [34]. The experimental data obtained herein illustrate a similar pattern of the decrease in $\mathrm{pH}$ of the culture medium, irrespective of the aeration rate. It should be noted in this case that the acidity of the samples declined most intensively without forced aeration and at a minimum aeration rate of $3.3 \mathrm{~L} / \mathrm{min}$ at the onset of the cultivation in the initial two days. 

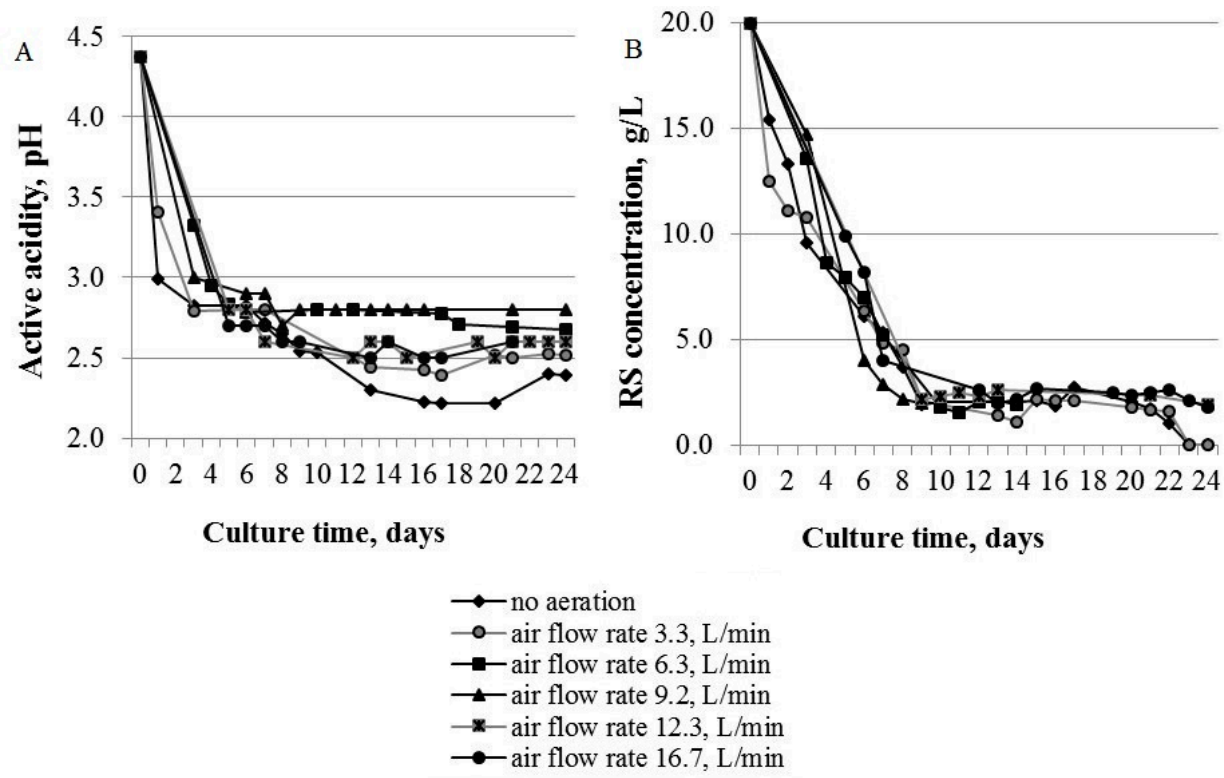

Figure 1. (A) Active acidity level and (B) reducing sugar (RS) concentration plotted against different aeration rates. The half-width of the confidence interval for $\mathrm{RS}$ concentration was $\pm 0.2 \mathrm{~g} / \mathrm{L}, \mathrm{pH} \pm 0.1$.

During the RS consumption, the first stage of fast RS utilization (from 0 to 10 days of cultivation) and the second stage of slow utilization (after 10 days of cultivation) were observed, which is typical of the Medusomyces gisevii Sa-12 microbial producer [29].

\subsubsection{BC Yield}

Figure 2 illustrates the $\mathrm{BC}$ yield as a function of the aeration mode.

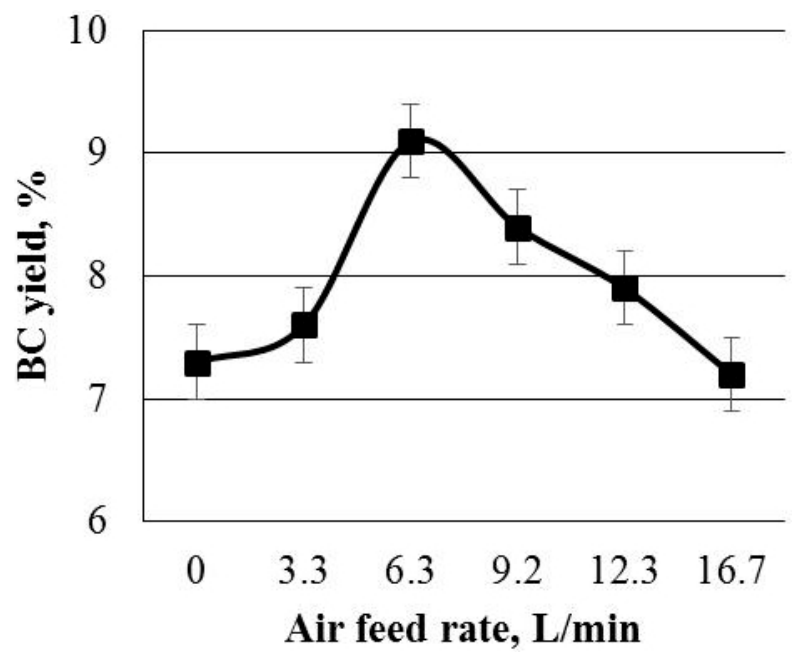

Figure 2. The bacterial cellulose (BC) yield plotted against the aeration rate.

The maximum BC yield of $9.1 \%$ was obtained at an air feed rate of $6.3 \mathrm{~L} / \mathrm{min}$. That is, this allowed a $25 \%$ increase in the BC yield as compared to the control. A decrease or further increase in the air feed rate caused the BC yield to decline to the baseline (7.2\%). When the aeration rate was lowered below $6.3 \mathrm{~g} / \mathrm{L}$, the $\mathrm{BC}$ yield reduction is explained by aerial oxygen deficiency that limited the $\mathrm{BC}$ biosynthesis process. When the aeration rate was raised above $6.3 \mathrm{~L} / \mathrm{min}$, the decreased $\mathrm{BC}$ yield is explained by the negative impact of excessive oxygen concentrations, which is in a good agreement with the literature data $[15,16]$. 
Kouda et al. [20] reported a $12.8 \%$ decrement in the BC yield when the partial oxygen pressure rose from 0.25 to $0.55 \mathrm{~atm}$ due to an increase in the air stream from 0.25 to $1.0 \mathrm{vvm}$.

Krusong et al. in their recent study [35] proposed a quite sophisticated way to overcome the known problem occurring during the aeration. The problem is that an increase in oxygen concentrations adversely affects the BC yield. The study suggested that a luffa sponge be used as a matrix and carboxymethylcellulose be added to the medium in order to mitigate the negative impact of excessive oxygen concentrations. The combination of these strategies allowed the authors to attain a BC yield comparable to that obtained under static culture.

In our study, the new aeration method by feeding the air onto the growth medium surface made it possible to achieve a progress in the BC technology. This simple strategy appeared to be a perfect alternative to the dynamic aeration method. Besides, the static culture combined with aeration furnished a higher BC yield than static culture alone.

\subsection{Characterization of BC Samples}

\subsubsection{Appearance of BC Gel-Films}

The fed air velocity differed considerably on different chamber shelves with forced aeration by which the air was fed on the growth medium surface. In the absence of aeration, as well as in climatic chamber sections located far away from the air streams, uniform BC pellciles were formed (Figure S1A, Supplementary Materials). In those chamber sections where air circulation was intensive (on the top of the chamber, near the fan), inhomogeneous BC gel-films were observed (Figure S1B, Supplementary Materials), as if a wave-like motion of the liquid was imprinted on the culture. Thus, even though the air was fed onto the surface rather than deep into the medium, distortions of the homogeneous structure of BC gel-films could not be avoided.

Table 1 summarizes a proportion of uniform gel-films depending on the aeration mode: the higher the air feed rate, the lower the proportion. When the air feed rate was raised above $6.3 \mathrm{~L} / \mathrm{min}$, the proportion of uniform gel-films became less than $70 \%$-which is undesirable.

Table 1. Bacterial cellulose (BC) yield and proportion of uniform gel-films subject to aeration mode.

\begin{tabular}{ccc}
\hline Aeration Rate, L/min & $\begin{array}{c}\text { Proportion of Uniform } \\
\text { Gel-Films, \% }\end{array}$ & BC Yield, \% \\
\hline No aeration (control) & 100 & $7.3 \pm 0.3$ \\
\hline 3.3 & $89.9 \pm 1.5$ & $7.6 \pm 0.3$ \\
\hline 6.3 & $72.4 \pm 2.2$ & $9.1 \pm 0.3$ \\
\hline 9.2 & $64.9 \pm 1.9$ & $8.4 \pm 0.3$ \\
\hline 12.3 & $60.7 \pm 2.5$ & $7.9 \pm 0.3$ \\
\hline 16.7 & $53.2 \pm 2.6$ & $7.2 \pm 0.3$ \\
\hline
\end{tabular}

The structural non-uniformity of BC gel-films limits their application fields.

\subsubsection{Microstructure of BC}

The ultrafine reticulate structure of $\mathrm{BC}$ nanofibers is an important fundamental property of BC [36]. Figure 3 shows SEM images of the reticulate structure of BC samples obtained with different air feed rates. 


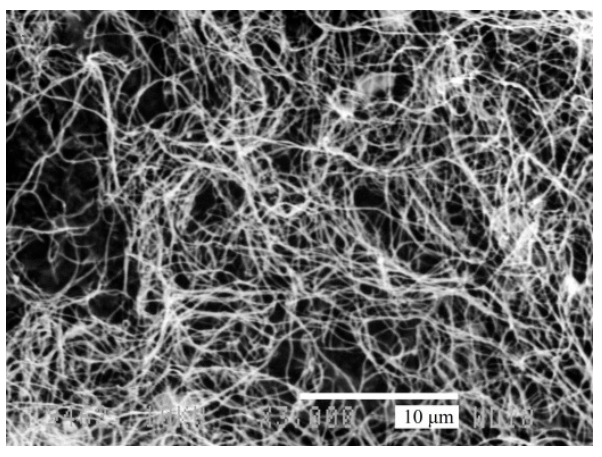

(a)

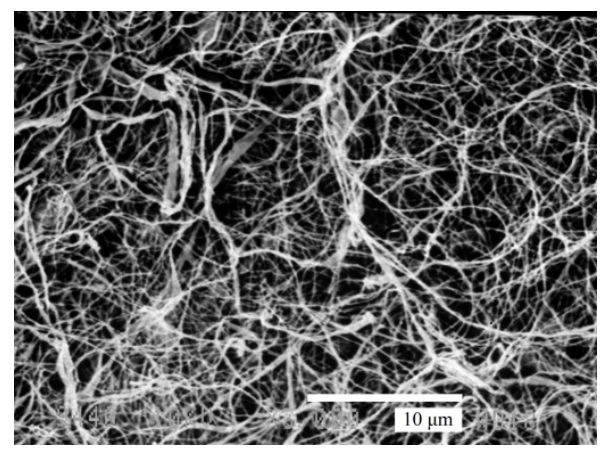

(d)

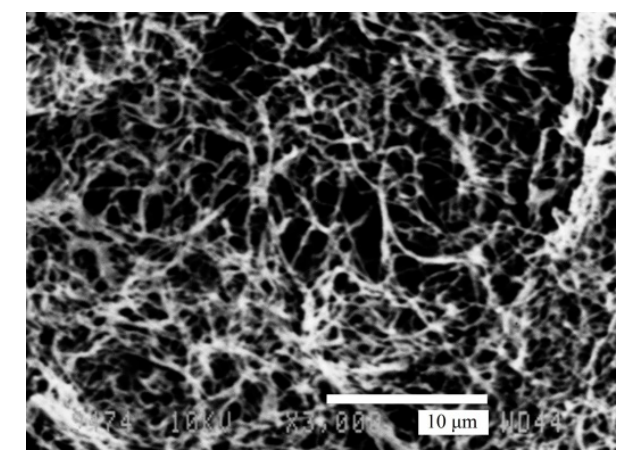

(b)

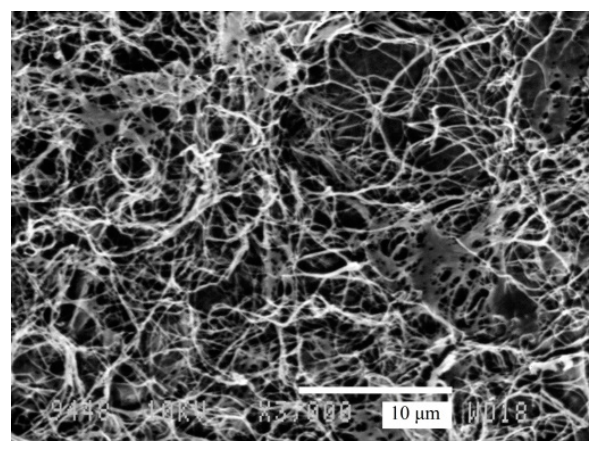

(e)

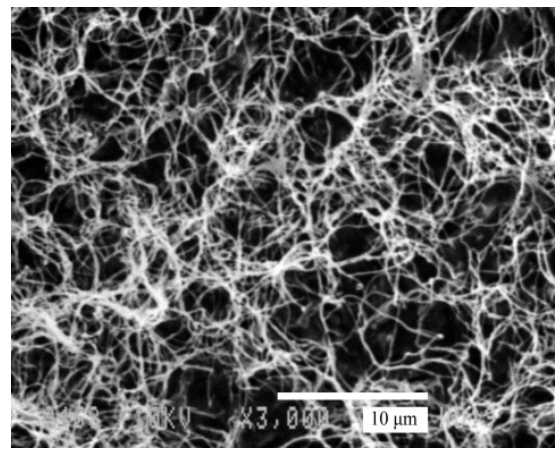

(c)

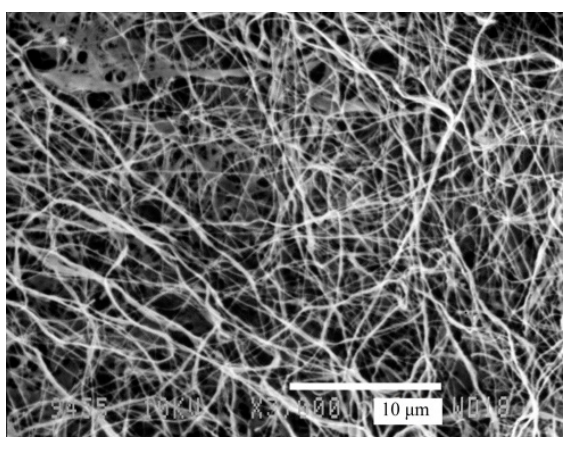

(f)

Figure 3. Scanning electron microscopy (SEM) micrograms of BC samples obtained at different air flow rates (L/min) (zoom $\times 3000$ ) (a) 0 (no aeration), (b) $3.3 \mathrm{~L} / \mathrm{min}$, (c) $6.3 \mathrm{~L} / \mathrm{min},(\mathbf{d}) 9.2 \mathrm{~L} / \mathrm{min}$, (e) $12.3 \mathrm{~L} / \mathrm{min}$, (f) $16.7 \mathrm{~L} / \mathrm{min}$.

Figure 3 illustrates that thickening or adhesion of $\mathrm{BC}$ nanofibers occurs at different aeration modes, with no clear relationship being traceable between the $\mathrm{BC}$ structure alteration and the aeration rate. However, the $3 \mathrm{D}$ irregular reticulate structure typical of $\mathrm{BC}$ is retained principally at all rates of air feeding onto the culture medium surface. This is a positive result.

The average widths of BC microfibrils (estimated with Image J software) are listed in Table 2. The relationship between the microfibril width and aeration rate was not found. A slight decline in the width of microfibrils was observed under aeration, but given the root-mean-square deviation value, this decline cannot be considered significant.

In contrast to the new aeration method proposed herein, the microstructure of $\mathrm{BC}$ is altered irreversibly when the air is fed deep into the culture medium [37]. The location of fibrils in agitated cultures is more widely spaced with a larger pore size. The formation of microfibrils is probably impaired by agitation during the fermentation process.

\subsubsection{BC Degree of Polymerization}

The highest degree of polymerization at 4300 was documented with no forced aeration. The degree of polymerization declined as the rate of air feeding onto the culture medium surface was raised. At the chosen aeration rate of $6.3 \mathrm{~L} / \mathrm{min}$, the degree of polymerization was 3800 , which is $12 \%$ lower that than in the control. When the air feed rate was elevated above $6.3 \mathrm{~L} / \mathrm{min}$, the degree of polymerization diminished dramatically. At the maximum air feed rate of $16.7 \mathrm{~L} / \mathrm{min}$, the degree of polymerization was the lowest, 950 or only $22 \%$ of the control value (Table 2).

This can be explained by activation of oxidative processes in cells of BC microbial producers and by disturbance of the function of enzyme systems. A decline in the degree of polymerization was noticed in other studies $[19,23,24]$ when dynamic culture and bioreactors were used. 
Table 2. Basic physicochemical characteristics of BC samples obtained at different aeration rates.

\begin{tabular}{|c|c|c|c|c|c|c|}
\hline \multirow[b]{2}{*}{ Parameter } & \multicolumn{6}{|c|}{ Aeration Rate, L/min } \\
\hline & $\begin{array}{c}\text { No } \\
\text { Aeration }\end{array}$ & 3.3 & 6.3 & 9.2 & 12.3 & 16.7 \\
\hline Average microfibril width, $\pm 40 \mathrm{~nm}$ & 107 & 93 & 81 & 101 & 85 & 97 \\
\hline Degree of polymerization, \pm 100 & 4300 & 4200 & 3800 & 2550 & 2100 & 950 \\
\hline Young's modulus, $\pm 10 \mathrm{MPa}$ & 910 & 860 & 795 & 490 & 360 & 315 \\
\hline \multicolumn{7}{|c|}{ TGA summary data } \\
\hline $\begin{array}{l}\text { Sample weight loss at the first stage, } \\
\qquad \pm 0.5 \%\end{array}$ & 4.1 & 5.0 & 3.9 & 4.5 & 4.1 & 2.8 \\
\hline $\begin{array}{l}\text { Sample weight loss at the second stage } \\
\text { (within sample decomposition range), } \\
\qquad 0.1 \%\end{array}$ & 7.8 & 17.9 & 12.4 & 19.5 & 37.4 & 19.1 \\
\hline $\begin{array}{l}\text { Onset temperature of decomposition, } \\
\qquad \pm 5^{\circ} \mathrm{C}\end{array}$ & 353 & 372 & 374 & 330 & 308 & 297 \\
\hline $\begin{array}{l}\text { Sample weight loss at the third stage, } \\
\qquad \pm 1.0 \%\end{array}$ & 62.5 & 49.2 & 63.6 & 52.4 & 30.4 & 45.7 \\
\hline $\begin{array}{l}\text { Sample weight loss at the fourth stage, } \\
\qquad \pm 0.5 \%\end{array}$ & 8.4 & 9.1 & 5.9 & 6.0 & 9.0 & 18.3 \\
\hline Unburnable residue, $\pm 1.0 \%$ & 17.2 & 18.9 & 14.3 & 17.6 & 19.1 & 14.2 \\
\hline \multicolumn{7}{|c|}{ Concentrations of cellulose allomorphs and crystallinity index as measured by $X$-ray diffraction } \\
\hline I $\alpha$-allomorph, $\pm 5 \%$ & 98 & 94 & 94 & 96 & 94 & 97 \\
\hline I $\beta$-allomorph, $\pm 5 \%$ & 2 & 6 & 6 & 4 & 6 & 3 \\
\hline $\begin{array}{c}\text { Index of crystallinity } \\
\text { (reflection geometry), } \pm 5 \%\end{array}$ & 93 & 93 & 89 & $87-90$ & 93 & 91 \\
\hline $\begin{array}{c}\text { Index of crystallinity } \\
\text { (transmission geometry), } \pm 5 \%\end{array}$ & 89 & 95 & 92 & 92 & 93 & 92 \\
\hline Crystallite size of $\langle 110\rangle, \pm 0.5 \mathrm{~nm}$ & 7.7 & 7.8 & 7.8 & 7.8 & 7.8 & 7.7 \\
\hline
\end{tabular}

\subsubsection{BC Elastic Modulus}

Similarly to the changes in the degree of polymerization, the elastic modulus was observed to decline as the aeration rate was elevated. The elastic modulus was $910 \mathrm{MPa}$ without aeration, while it decreased 2.9-fold and was $315 \mathrm{MPa}$ at a maximum aeration rate of $16.7 \mathrm{~L} / \mathrm{min}$. Also, the critical point, after which the elastic modulus was observed to decline sharply, was when the air feed rate was raised above $6.3 \mathrm{~L} / \mathrm{min}$ (Table 2). At an aeration rate of $6.3 \mathrm{~L} / \mathrm{min}$, the elastic modulus was $795 \mathrm{MPa}$, which is $12.6 \%$ lower than that of the control.

\subsubsection{Thermogravimetric Analysis (TGA)}

TGA data dependences on the aeration mode were not observed (Table 2). The highest onset temperature of decomposition was for the sample obtained at an air flow rate of $6.3 \mathrm{~L} / \mathrm{min}$, that is, the sample was the most thermally stable and purest [38]. The other values of $\mathrm{BC}$ decomposition temperature and weight loss did not correlate between each other and did not depend on the aeration mode. But it can be said in summary that these are close values evidencing more of similarities of the samples rather than their dissimilarities.

It is generally believed that the behavior of the sample when thermally decomposed is influenced by factors such as molecular weight, crystallinity, degree of polymerization, and compactness of structural interlacement [39].

We believe that the impurities, but not the BC structure, affect most notably the TGA analysis. Because the proportion of inhomogeneous BC gel-films increased as the air feed 
rate was raised, it is the structural non-uniformity that governs the unequal quality of $\mathrm{BC}$ washing free of impurities.

The comparison of the TGA data for the BC samples obtained in this study with those reported in the literature demonstrated that the results are alike [38].

\subsubsection{X-ray Diffraction}

The index of crystallinity varied within the range from $87 \%$ to $93 \%$ in reflection geometry and from $89 \%$ to $95 \%$ in transmission geometry, and the allomorph I $\alpha$ content ranged from $94 \%$ to $98 \%$, regardless of the aeration mode. With the chosen aeration mode of $6.3 \mathrm{~L} / \mathrm{min}$, the indices of crystallinity were $89 \%$ in reflection geometry and $92 \%$ in transmission geometry, and the allomorph I $\alpha$ content was $94 \%$. The size of crystallites did not depend on aeration rate (Table 2), as in the study [40] in which the size of crystallites did not change when the biofilm reactor was used. It can be inferred that the X-ray structural characteristics of BC samples do not depend on the aeration mode.

The literature describes a considerable decrease in the BC index of crystallinity when dynamic aeration methods are used. It is indicated that the structural variation of BC is accompanied by the alteration of its physicochemical properties $[17,20,24]$.

The fact that the basic X-ray structural characteristics of BC samples are independent of the aeration mode, as established in the present study, is explained not only by the optimum aeration conditions found, but also by the properties of the microbial producer used-Medusomyces gisevii Sa-12. Our previous study discovered that the quality of BC produced by Medusomyces gisevii Sa-12 under unsterile conditions does not depend on the composition of hydrolyzate media. The hydrolyzate media were derived from Miscanthus by four chemical pretreatment methods, followed by enzymatic hydrolysis [41].

Orlovska et al. [42] investigated the behavior of the microecosystem of the tea fungus culture (i.e., Medusomyces gisevii Sa-12) and the quality of the produced BC, through the means of simulating the Mars-like environment. They documented a high survivability of the tea fungus culture and a decrease in the BC yield, but the structural characteristics of $\mathrm{BC}$ in this case showed no significant changes in all of the trials.

Thus, the Medusomyces gisevii Sa-12 symbiotic culture is capable of synthesizing stablequality BC, irrespective of the cultivation conditions such as the composition of media used, sterility-free media, aeration modes, and biosynthesis under extreme conditions. By the totality of factors, symbiotic Medusomyces gisevii Sa-12 demonstrates undisputable merits for industrial application.

Forte et al. [43] note that the manufacture of BC by using individual strains under production environments is quite limited, whereas the production of BC by using symbiotic cultures is traditionally widely practiced in the Asian-Pacific Region. The production of BC by a using symbiotic culture currently continues to broaden, including that for technical applications [25,44-46].

The BC gel-films produced in the present study were employed to fabricate composite paper using hardwood pulp [47]. We noted that despite the resultant BC gel-films being inhomogeneous, their basic properties such as moisture, water-holding capacity, and X-ray structural properties (allomorph I $\alpha$ content and index of crystallinity) remained stable. Because the samples were ground for use as a part of the composites, the differences in parameters such as degree of polymerization and elastic modulus are not critical.

\section{Conclusions}

Here we have successfully combined static biosynthesis of BC with forced aeration. The new aeration method by which the air is fed onto the culture medium surface at a rate of $6.3 \mathrm{~L} / \mathrm{min}$ allows a $25 \%$ increase in the BC yield. The biosynthesis performed at this aeration rate furnished $\mathrm{BC}$ samples of stable quality. The thermogravimetric and X-ray structural characteristics remained unchanged: the index of crystallinity was $89 \%$ in reflection geometry and $92 \%$ in transmission geometry, and the allomorph I $\alpha$ content was $94 \%$. The decline in the degree of polymerization by $12.0 \%$ (3800 versus 4300 ) and in elastic modulus by $12.6 \%$ 
(795 MPa versus $910 \mathrm{MPa}$ ), when compared to the control with no aeration, is not critical. The stability of the parameters of BC samples under varying aeration conditions is explained by the concomitant factors: the new effective aeration method and the high adaptivity of the microbial producer-symbiotic Medusomyces gisevii Sa-12.

Supplementary Materials: The following are available online at https:/ /www.mdpi.com/article/10 .3390 / polym13234241/s1, Figure S1. Photographs of BC samples.

Author Contributions: Conceptualization, E.A.S.; methodology, N.A.S.; validation, E.A.S., G.F.M., Y.A.G., E.I.K.; formal analysis, E.A.S.; investigation, A.E.K., N.V.B., A.A.K., I.N.P.; writing-original draft preparation, N.A.S.; writing—review and editing, V.V.B., E.K.G.; supervision, G.V.S. All authors have read and agreed to the published version of the manuscript.

Funding: This research was funded by the Russian Science Foundation, grant number 17-19-01054.

Institutional Review Board Statement: Not applicable.

Informed Consent Statement: Not applicable.

Data Availability Statement: The data presented in this study are available upon request from the corresponding author.

Conflicts of Interest: The authors declare no conflict of interest.

\section{References}

1. Wang, J.; Tavakoli, J.; Tang, Y. Bacterial cellulose production, properties and applications with different culture methods-A review. Carbohydr. Polym. 2019, 219, 63-67. [CrossRef] [PubMed]

2. Klemm, D.; Petzold-Welcke, K.; Kramer, F.; Richter, T.; Raddatz, V.; Fried, W.; Nietzsche, S.; Bellmann, T.; Fischer, D. Biotech nanocellulose: A review on progress in product design and today's state of technical and medical applications. Carbohydr. Polym. 2020, 254, 117313. [CrossRef]

3. Bodea, I.M.; Beteg, F.I.; Pop, C.R.; David, A.P.; Dudescu, M.C.; Vilău, C.; Stănilă, A.; Rotar, A.M.; Catunescu, G.M. Optimi-zation of moist and oven-dried bacterial cellulose production for functional properties. Polymers 2021, 13, 2088. [CrossRef]

4. Revin, V.; Dolganov, A.; Liyaskina, E.; Nazarova, N.; Balandina, A.; Devyataeva, A.; Revin, V. Characterizing Bacterial Cellulose Produced byKomagataeibacter sucrofermentans H-110 on Molasses Medium and Obtaining a Biocomposite Based on It for the Adsorption of Fluoride. Polymers 2021, 13, 1422. [CrossRef] [PubMed]

5. Abol-Fotouh, D.; Hassan, M.A.; Shokry, H.; Roig, A.; Azab, M.S.; Kashyout, A.E.-H.B. Bacterial nanocellulose from agro-industrial wastes: Low-cost and enhanced production by Komagataeibacter saccharivorans MD1. Sci. Rep. 2020, 10, 1-14. [CrossRef]

6. Sharma, C.; Bhardwaj, N.K. Bacterial nanocellulose: Present status, biomedical applications and future perspectives. Mater. Sci. Eng. C 2019, 104, 109963. [CrossRef] [PubMed]

7. Podgorbunskikh, E.M.; Bychkov, A.L.; Lomovsky, O.I. Determination of Surface Accessibility of the Cellulose Substrate According to Enzyme Sorption. Polymers 2019, 11, 1201. [CrossRef]

8. Daskalova, A.; Angelova, L.; Filipov, E.; Aceti, D.; Mincheva, R.; Carrete, X.; Kerdjoudj, H.; Dubus, M.; Chevrier, J.; Trifonov, A.; et al. Biomimetic Hierarchical Structuring of PLA by Ultra-Short Laser Pulses for Processing of Tissue Engineered Matrices: Study of Cellular and Antibacterial Behavior. Polymers 2021, 13, 2577. [CrossRef] [PubMed]

9. Gregory, D.A.; Tripathi, L.; Fricker, A.T.R.; Asare, E.; Orlando, I.; Raghavendran, V.; Roy, I. Bacterial cellulose: A smart biomaterial with diverse applications. Mater. Sci. Eng. R Rep. 2021, 145, 100623. [CrossRef]

10. Mbituyimana, B.; Liu, L.; Ye, W.; Boni, B.O.O.; Zhang, K.; Chen, J.; Thomas, S.; Vasilievich, R.V.; Shi, Z.; Yang, G. Bacterial cellulose-based composites for biomedical and cosmetic applications: Research progress and existing products. Carbohydr. Polym. 2021, 273, 118565. [CrossRef]

11. Shirai, A.; Takahashi, M.; Kaneko, H.; Nishimura, S.-I.; Ogawa, M.; Nishi, N.; Tokura, S. Biosynthesis of a novel polysaccharide by Acetobacter xylinum. Int. J. Biol. Macromol. 1994, 16, 297-300. [CrossRef]

12. Aloni, Y.; Delmer, D.P.; Benziman, M. Achievement of high rates of in vitro synthesis of 1,4-beta-D-glucan: Activation by cooperative interaction of the Acetobacter xylinum enzyme system with GTP, polyethylene glycol, and a protein factor. Proc. Natl. Acad. Sci. USA 1982, 79, 6448-6452. [CrossRef]

13. Hu, Y.; Catchmark, J.; Vogler, E. Factors impacting the formation of sphere-like bacterial cellulose particles and their biocompatibility for human osteoblast growth. Biomacromolecules 2013, 14, 3444-3452. [CrossRef] [PubMed]

14. Cai, Q.; Hu, C.; Yang, N.; Wang, Q.; Wang, J.; Pan, H.; Hu, Y.; Ruan, C. Enhanced activity and stability of industrial lipases immobilized onto spherelike bacterial cellulose. Int. J. Biol. Macromol. 2017, 109, 1174-1181. [CrossRef]

15. Czaja, W.; Romanovicz, D.; Brown, R.M. Structural investigations of microbial cellulose produced in stationary and agitated culture. Cellulose 2004, 11, 403-411. [CrossRef] 
16. Tantratian, S.; Tammarate, P.; Krusong, W.; Bhattarakosol, P.; Phunsri, A. Effect of dissolved oxygen on cellulose production by Acetobacter sp. J. Sci. Res. Chula. Univ. 2005, 30, 179-186.

17. Krystynowicz, A.; Czaja, W.; Wiktorowska-Jezierska, A.; Goncalves-Miskiewicz, M.; Turkiewicz, M.; Bielecki, S. Factors af-fecting the yield and properties of bacterial cellulose. J. Ind. Microbiol. Biotechnol. 2002, 29, 189-195. [CrossRef] [PubMed]

18. Huang, Y.; Zhu, C.; Yang, J.; Nie, Y.; Chen, C.; Sun, D. Recent advances in bacterial cellulose. Cellulose 2013, 21, 1-30. [CrossRef]

19. Kouda, T.; Yano, H.; Yoshinaga, F.; Kaminoyama, M.; Kamiwano, M. Characterization of non-newtonian behavior during mixing of bacterial cellulose in a bioreactor. J. Ferment. Bioeng. 1996, 82, 382-386. [CrossRef]

20. Kouda, T.; Naritomi, T.; Yano, H.; Yoshinaga, F. Effects of oxygen and carbon dioxide pressures on bacterial cellulose pro-duction by Acetobacter in aerated and agitated culture. J. Ferment. Bioeng. 1997, 84, 124-127. [CrossRef]

21. Chao, Y.; Sugano, Y.; Shoda, M. Bacterial cellulose production under oxygen-enriched air at different fructose concentrations in a 50-liter, internal-loop airlift reactor. Appl. Microbiol. Biotechnol. 2001, 55, 673-679. [CrossRef]

22. Wu, S.-C.; Li, M.-H. Production of bacterial cellulose membranes in a modified airlift bioreactor by Gluconacetobacter xylinus. J. Biosci. Bioeng. 2015, 120, 444-449. [CrossRef] [PubMed]

23. Song, H.-J.; Li, H.; Seo, J.-H.; Kim, M.-J.; Kim, S.-J. Pilot-scale production of bacterial cellulose by a spherical type bubble column bioreactor using saccharified food wastes. Korean J. Chem. Eng. 2009, 26, 141-146. [CrossRef]

24. Zahan, K.A.; Pa'e, N.; Muhamad, I.I. An evaluation of fermentation period and discs rotation speed of rotary discs reactor for bacterial cellulose production. Sains Malays. 2016, 45, 393-400.

25. Zhong, C. Industrial-Scale Production and Applications of Bacterial Cellulose. Front. Bioeng. Biotechnol. 2020, 8. [CrossRef]

26. Chakravorty, S.; Bhattacharya, S.; Chatzinotas, A.; Chakraborty, W.; Bhattacharya, D.; Gachhui, R. Kombucha tea fermen-tation: Microbial and biochemical dynamics. Int. J. Food Microbiol. 2016, 220, 63-72. [CrossRef]

27. Marsh, A.J.; O'Sullivan, O.; Hill, C.; Ross, R.; Cotter, P.D. Sequence-based analysis of the bacterial and fungal compositions of multiple kombucha (tea fungus) samples. Food Microbiol. 2013, 38, 171-178. [CrossRef]

28. Sharma, C.; Bhardwaj, N.K. Biotransformation of fermented black tea into bacterial nanocellulose via symbiotic interplay of microorganisms. Int. J. Biol. Macromol. 2019, 132, 166-177. [CrossRef]

29. Gladysheva, E.K.; Skiba, E.A.; Zolotukhin, V.; Sakovich, G.V. Study of the Conditions for the Biosynthesis of Bacterial Cellulose by the Producer Medusomyces gisevii Sa-12. Appl. Biochem. Microbiol. 2018, 54, 179-187. [CrossRef]

30. Shavyrkina, N.; Budaeva, V.; Skiba, E.; Mironova, G.; Bychin, N.; Gismatulina, Y.; Kashcheyeva, E.; Sitnikova, A.; Shilov, A.; Kuznetsov, P.; et al. Scale-Up of Biosynthesis Process of Bacterial Nanocellulose. Polymers 2021, 13, 1920. [CrossRef]

31. Hallac, B.B.; Ragauskas, A.J. Analyzing cellulose degree of polymerization and its relevancy to cellulosic ethanol. Biofuels Bioprod. Biorefin. 2011, 5, 215-225. [CrossRef]

32. French, A.D. Idealized powder diffraction patterns for cellulose polymorphs. Cellulose 2013, 21, 885-896. [CrossRef]

33. French, A.D. Increment in evolution of cellulose crystallinity analysis. Cellulose 2020, 27, 5445-5448. [CrossRef]

34. Yurkevich, D.I.; Kutyshenko, V.P. Medusomyces (Tea fungus): A scientific history, composition, features of physiology and metabolism. Biophysics 2002, 47, 1035-1048.

35. Krusong, W.; Pothimon, R.; La China, S.; Thompson, A.K. Consecutive bacterial cellulose production by luffa sponge enmeshed with cellulose microfibrils of Acetobacter xylinum under continuous aeration. 3 Biotech 2021, 11, 1-9. [CrossRef]

36. Gama, M.; Dourado, F.; Bielecki, S. Bacterial nanocellulose. From Biotechnology to Bio-Economy, 1st ed.; Elsevier: Amsterdam, Netherlands, 2016.

37. Singhsa, P.; Narain, R.; Manuspiya, H. Physical structure variations of bacterial cellulose produced by different Komaga-taeibacter xylinus strains and carbon sources in static and agitated conditions. Cellulose 2018, 25, 1571-1581. [CrossRef]

38. Pacheco, G.; Nogueira, C.; Meneguin, A.; Trovatti, E.; Silva, M.C.; Machado, R.T.; Ribeiro, S.; Filho, E.S.; Barud, H.D.S. Development and characterization of bacterial cellulose produced by cashew tree residues as alternative carbon source. Ind. Crop. Prod. 2017, 107, 13-19. [CrossRef]

39. Um, I.C.; Ki, C.S.; Kweon, H.Y.; Lee, K.G.; Ihm, D.W.; Park, Y.H. Wet spinning of silk polymer II. Effect of drawing on the structure characteristics and properties of filament. Int. J. Biol. Macromol. 2004, 34, 107-119. [CrossRef]

40. Cheng, K.-C.; Catchmark, J.M.; Demirci, A. Enhanced Production of Bacterial Cellulose Production by Using Biofilm Reactor and its Material Property Analysis. J. Biol. Eng. 2009. [CrossRef]

41. Skiba, E.; Gladysheva, E.K.; Golubev, D.S.; Budaeva, V.V.; Aleshina, L.; Sakovich, G.V. Self-standardization of quality of bacterial cellulose produced by Medusomyces gisevii in nutrient media derived from Miscanthus biomass. Carbohydr. Polym. 2020, 252, 117178. [CrossRef]

42. Orlovska, I.; Podolich, O.; Kukharenko, O.; Zaets, I.; Reva, O.; Khirunenko, L.; Zmejkoski, D.; Rogalsky, S.; Barh, D.; Tiwari, S.; et al. Bacterial Cellulose Retains Ro-bustness but Its Synthesis Declines After Exposure to a Mars-Like Environment Simulated Outside the International Space Station. Astrobiology 2021, 21, 706-717. [CrossRef] [PubMed]

43. Forte, A.; Dourado, F.; Mota, A.; Neto, B.; Gama, M.; Ferreira, E.C. Life cycle assessment of bacterial cellulose production. Int. J. Life Cycle Assess. 2021, 26, 864-878. [CrossRef]

44. Pillai, M.M.; Tran, H.N.; Sathishkumar, G.; Manimekalai, K.; Yoon, J.; Lim, D.; Noh, I.; Bhattacharyya, A. Symbiotic culture of nanocellulose pellicle: A potential matrix for 3D bioprinting. Mater. Sci. Eng. C 2020, 119, 111552. [CrossRef] [PubMed]

45. Nguyen, H.T.; Saha, N.; Ngwabebhoh, F.A.; Zandraa, O.; Saha, T.; Saha, P. Kombucha-derived bacterial cellulose from diverse wastes: A prudent leather alternative. Cellulose 2021, 28, 9335-9353. [CrossRef] 
46. Laavanya, D.; Shirkole, S.; Balasubramanian, P. Current challenges, applications and future perspectives of SCOBY cellulose of Kombucha fermentation. J. Clean. Prod. 2021, 295, 126454. [CrossRef]

47. Gismatulina, Y.A.; Budaeva, V.V.; Sitnikova, A.E.; Bychin, N.V.; Gladysheva, E.K.; Shavyrkina, N.A.; Mironova, G.F.; Sevastyanova, Y.V. Bacterial nanocellulose and softwood pulp for composite paper. Proc. Univ. Appl. Chem. Biotechnol. 2021, 11, 460-471. [CrossRef] 